\title{
Microstructure, deformation and cracking characteristics of thermal spray ferrous coatings
}

\author{
A. Rabiei ${ }^{\text {a,*}}{ }^{\text {, D.R. Mumm }}{ }^{\text {a }}$, J.W. Hutchinson ${ }^{\text {a }}$, R. Schweinfest ${ }^{\text {c }}$, M. Rühle ${ }^{\text {c }}$, \\ A.G. Evans ${ }^{b}$ \\ ${ }^{a}$ Division of Engineering and Applied Sciences, Harvard University, 40 Oxford Street, Cambridge, MA 02138, USA \\ b Princeton Materials Institute, Bowen Hall, 70 Prospect Avenue, Princeton, NJ 08540, USA \\ ${ }^{\mathrm{c}}$ Max Planck Institute, Stuttgart, Germany
}

Received 16 December 1998; received in revised form 5 March 1999; accepted 8 March 1999

\begin{abstract}
The microstructure and local mechanical characteristics of thermal spray ferrous coatings have been determined. The emphasis has been on coatings made by the high velocity oxyfuel (HVOF) process, especially the role of Al alloy additives. The oxide phase present in the material and preferred pathways for local cracking and separation have been determined. Thin intersplat oxide layers emerge as preferential sites. These oxides are amorphous and the cracks extend along the oxide/ $\alpha-\mathrm{Fe}$ interfaces with low local fracture toughness, in the range $0.2-1 \mathrm{MPa} / \mathrm{m}$. These low toughness pathways govern coating deterioration. (C) 1999 Elsevier Science S.A. All rights reserved.
\end{abstract}

Keywords: Thermal spray coating; Local fracture toughness; Indentation test; High velocity oxyfuel process; Plasma transfer wire arc process; Atomic force microscopy

\section{Introduction}

Ferrous thermal spray coatings are of interest in various industry sectors for the protection of surfaces against elevated temperature degradation and wear [1-12]. The most prominent application is in the automotive industry as protective bore coatings on cast Al alloy cylinder blocks. Traditionally, blocks have been made entirely of gray cast iron. It is estimated [13], however, that by the year 2000 nearly half of all engine blocks manufactured, worldwide, will be made of aluminum alloys. This change is brought about by the need to reduce vehicle weight in order to improve fuel economy. But, the sliding of a piston against an unprotected aluminum bore leads to unacceptable wear, degrading both the compression and emission characteristics of the engine. Currently, cast iron lin-

\footnotetext{
* Corresponding author. Tel.: + 1-617-495-8454; fax: + 1-617-4969771.

E-mail address: rabiei@esag.harvard.edu (A. Rabiei)
}

ers are used to obviate these problems. However, these add weight and cost, as well as decrease cylinder displacement. Thus, automotive companies worldwide are developing Fe-based wear-resistant coatings for the bores [1]. These thin $(\sim 200 \mu \mathrm{m})$ coatings are prepared by a thermal spray process in which, typically, Fe-alloy wire is melted and the droplets are sprayed onto the bore surface [2-5,12]. The resultant coating is a composite of the alloy with oxides resulting from oxidation during deposition [12]. This coating represents a tribological surface upon which much of the automotive industry will depend in the future. Despite their importance, few basic properties of these coatings have been measured [7]. One consequence is that the impact of microstructure and phase content on performance cannot be predicted.

There are few open literature reports on the microstructure and properties of these materials $[1,12,14]$. In this article, a range of such coatings have been investigated, some produced by the high velocity oxyfuel (HVOF) process [3,12] and others by the plasma transfer wire arc (PTWA) process [6]. The objective is to establish some of the basic microstruc- 
Table 1

Chemical compositions of coatings

\begin{tabular}{llllllll}
\hline Material & \multicolumn{6}{c}{ Composition (wt.\%) } \\
\cline { 3 - 8 } & & $\mathrm{Al}$ & $\mathrm{Mg}$ & $\mathrm{Si}$ & $\mathrm{C}$ & $\mathrm{Mn}$ & $\mathrm{O}_{2}$ \\
\hline \multirow{4}{*}{ HVOF } & $\mathrm{A}$ & 0 & 1.0 & 0.22 & 0 & 0 & 11 \\
& $\mathrm{~B}$ & 0.05 & 0.01 & 0.06 & 0 & 0 & 12 \\
& $\mathrm{C}$ & 3.7 & 1.05 & 0.44 & 0 & 0 & 0.9 \\
& $\mathrm{D}$ & 2.1 & 0.08 & 0.3 & 0 & 0 & 4 \\
PTWA & E & 2.6 & 0.12 & 0.2 & 0 & 0 & 2.7 \\
& $\mathrm{G}$ & 0 & 0 & 0.01 & 0.1 & 0.42 & 5.5 \\
& $\mathrm{~F}$ & - & - & - & - & - & - \\
\hline
\end{tabular}

tural characteristics of these materials and to relate the microstructure to those local mechanical responses that affect their performance, particularly in wear and pullout.

From an applications perspective, one of the factors that dictates utility is the ability of the coating to resist material removal in a sliding wear situation. Such removal involves material pull-out from the coating surface, by a local microcracking mechanism occurring on the scale of individual splats. The severity of this mechanism is governed by the fracture toughness of the coating at this small, physical scale. One goal of this article is to probe the fracture toughness properties at this level.

Most of the HVOF and PTWA coatings analyzed in this investigation were deposited on wrought $\mathrm{Al}$ alloys using the deposition systems at General Motors. One

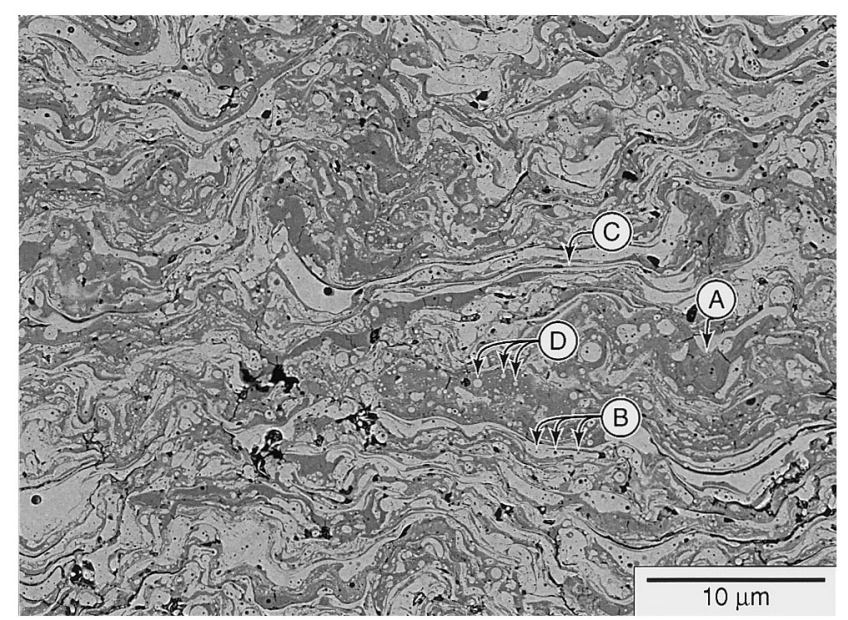

Fig. 1. A typical scanning electron microscopy (SEM) image of a cross section through a standard (category A/B) high velocity oxyfuel (HVOF) material. Region $\mathrm{A}$ is predominantly $\mathrm{FeO}$ formed in the liquid state. Region B identifies $\mathrm{FeO}$ precipitates in the Fe. Region $\mathrm{C}$ identifies the intersplat thin oxide layers. Region $\mathrm{D}$ identifies $\mathrm{Fe}$ precipitates in the $\mathrm{FeO}$ region.
PTWA material was acquired from Ford Motor. The ferrous wires comprised either conventional low alloy steels or specialty $\mathrm{Fe} / \mathrm{Al}$ alloys (Table 1 ) with variable Al content.

\section{Characterization procedures}

Various microscopies and spectroscopies have been used to characterize the microstructure of the coatings. Optical as well as scanning electron microscopies (SEM) have been performed on cross sections. Transmission electron microscopy (TEM) conducted on thin foils has provided structural and analytic information at resolutions relevant to local mechanical responses. The analytical mode in the SEM was used to provide
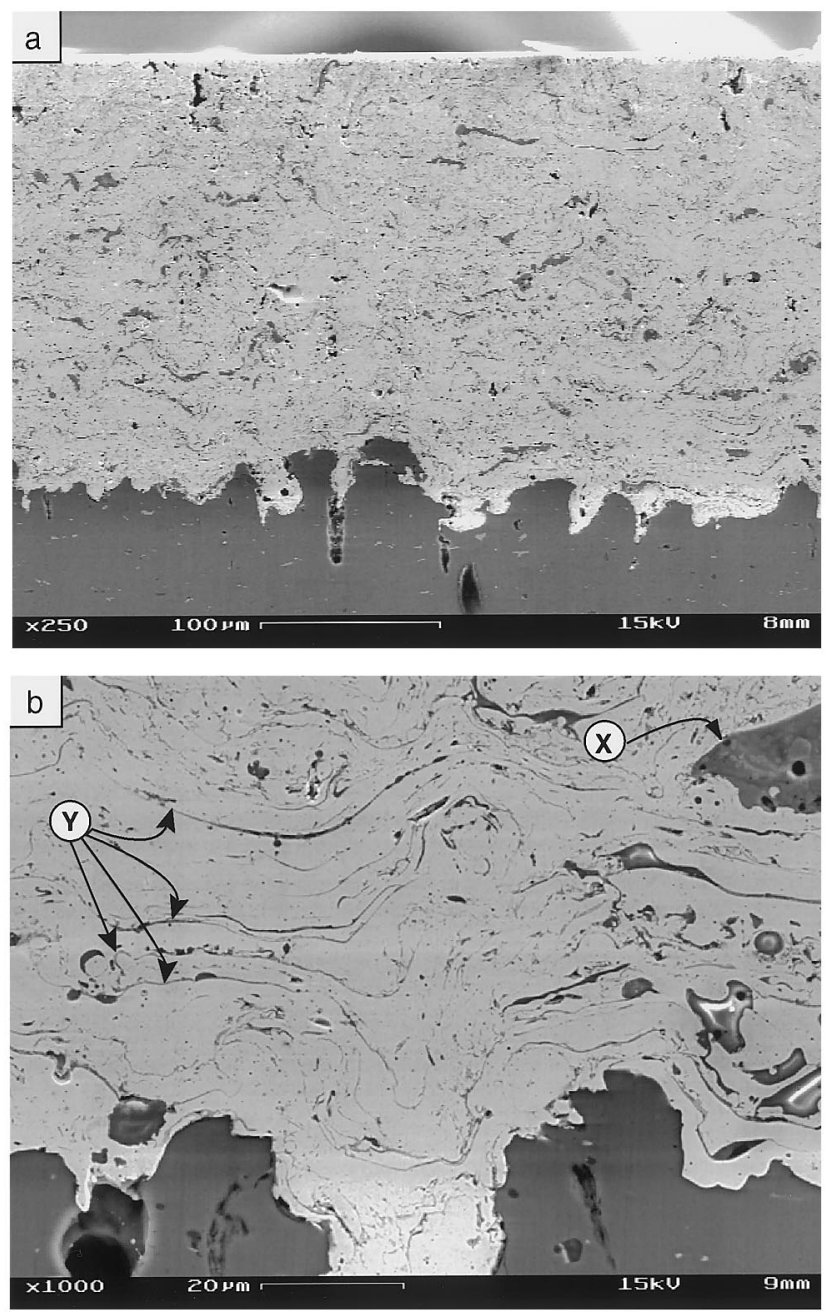

Fig. 2. Scanning electron microscopy (SEM) images of the high velocity oxyfuel (HVOF) coatings made using $\mathrm{Fe} / \mathrm{Al}$ alloys (category $\mathrm{C}-\mathrm{E}$ ). (a) General overview; (b) high resolution image. Region $\mathrm{X}$ identifies a two phase oxide inclusion. Region Y identifies intersplat oxide thin layers. 


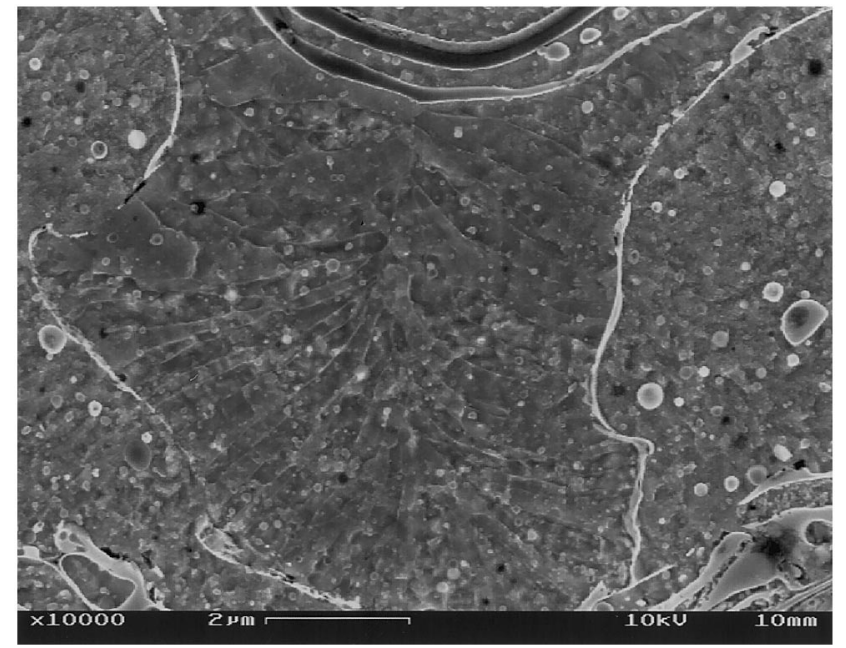

Fig. 3. A scanning electron microscopy (SEM) image of an etched cross section of a high velocity oxyfuel (HVOF) coating made from $\mathrm{Fe} / \mathrm{Al}$, revealing the columnar grains and the continuous thin oxide around the splat boundary. The shape of this splat is atypical, but visually the most illustrative.

chemical information. Surface topologies were characterized using the atomic force microscope (AFM). The specimen preparation procedures and the methods of analysis are elaborated below.

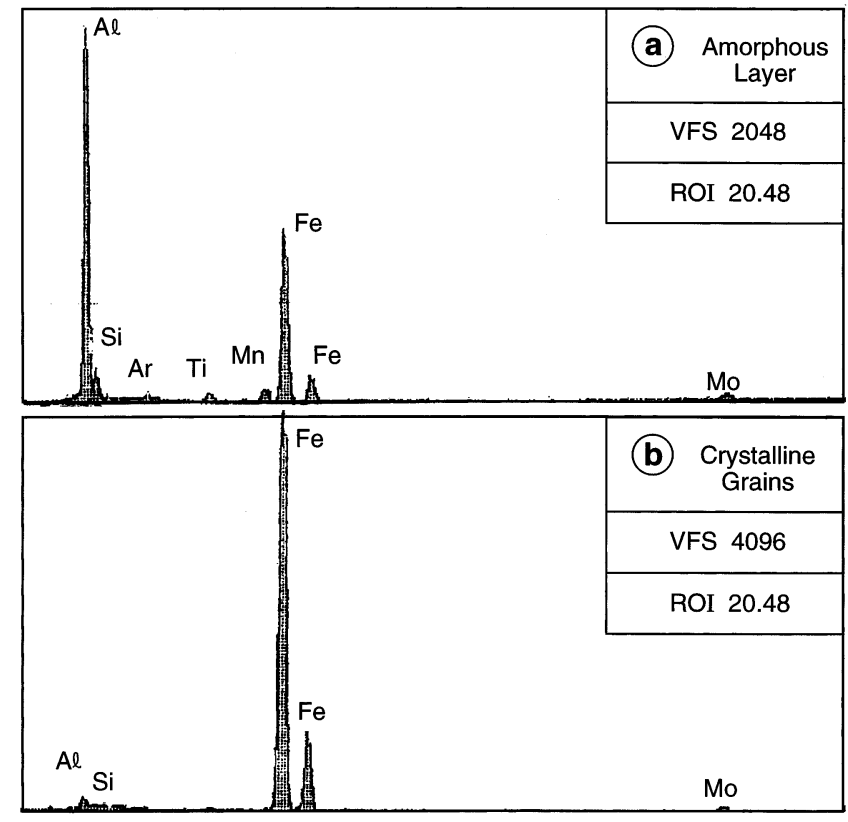

Fig. 5. (a) Energy dispersive X-ray (EDX) analysis of the amorphous oxide layer.(b) EDX analysis of one of the crystalline $\alpha-\mathrm{Fe}$ domains contiguous with the oxide interlayer.

(b)

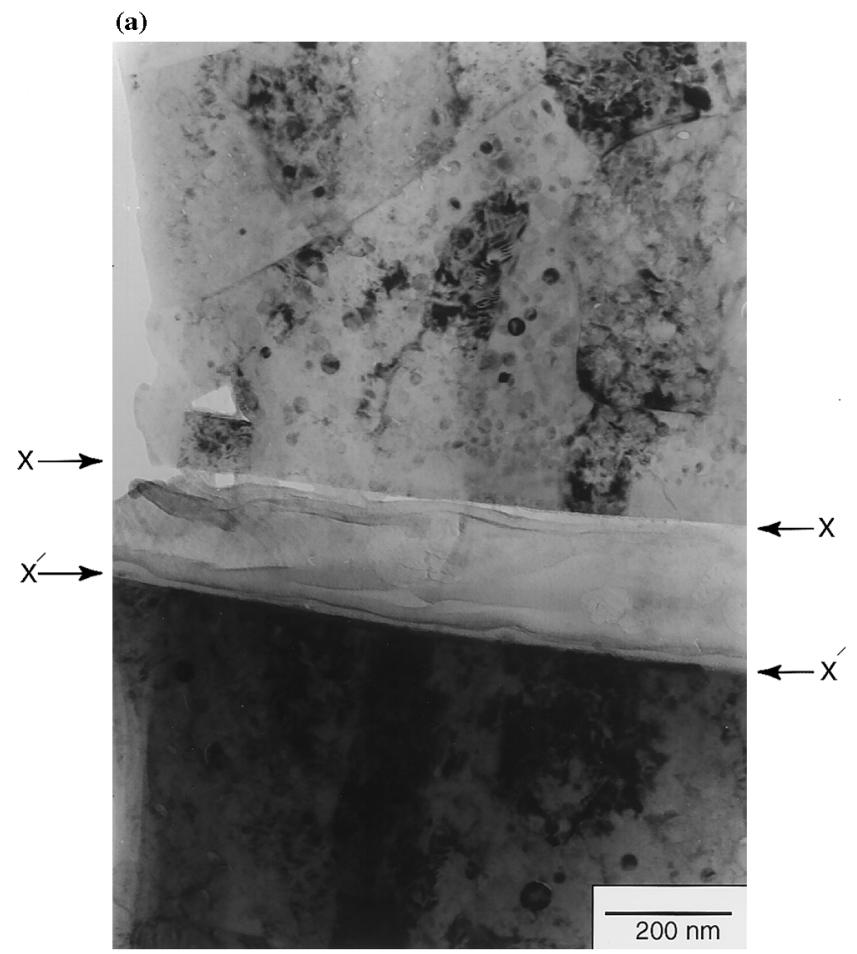

Fig. 4. (a) Bright field transmission electron microscopy (TEM) image of o

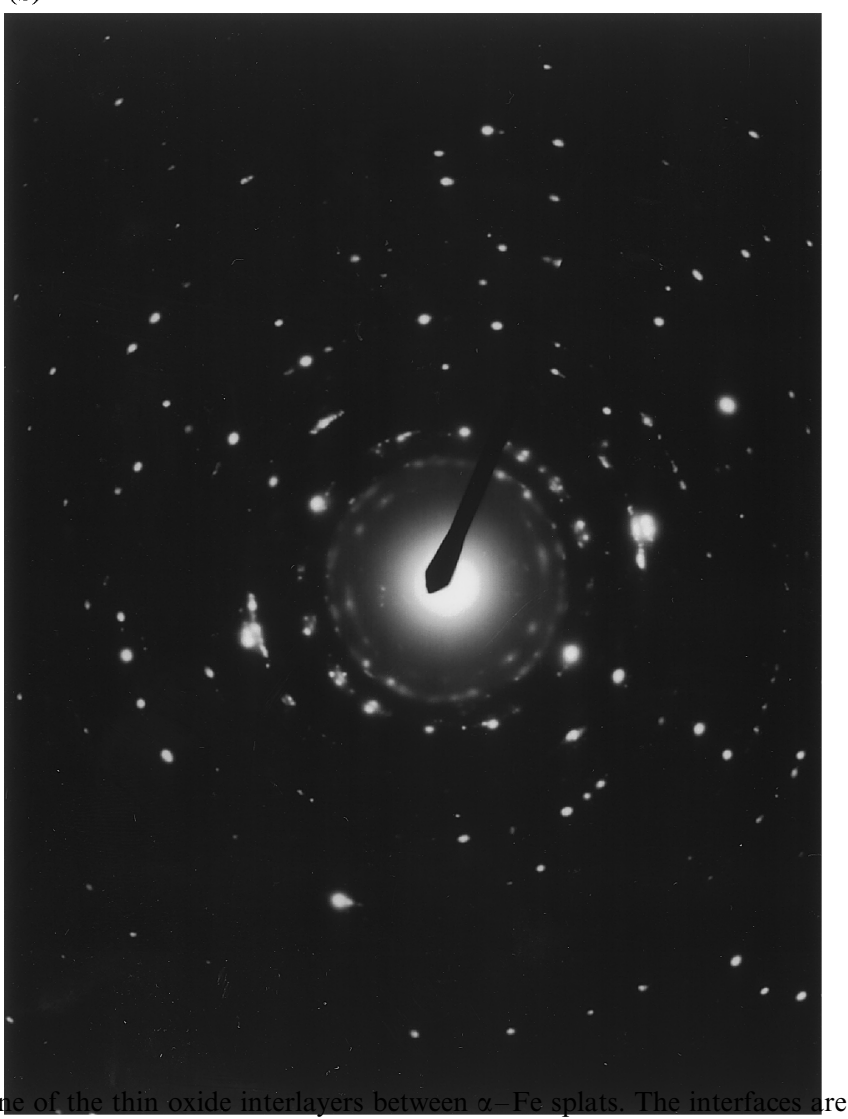
along $\mathrm{XX}$ and $\mathrm{X}^{\prime} \mathrm{X}^{\prime}$ with the amorphous layer enclosed. Precipitates are evident within the $\alpha-\mathrm{Fe}$, especially at the top. (b) Selected area electron diffraction (SAD) pattern of a region that includes the oxide layer reveals that it is amorphous. 


\subsection{Cross sections}

Cross sections were prepared by mechanical polishing. The sections were cut by electro-discharge machining, in order to minimize damage. One side was polished with sequential mechanical media comprising 6, 3 and $1 \mu \mathrm{m}$ diamond pastes, with a finish achieved by submicron diamond suspension embedded in a soft disk. This procedure provided an optical quality surface.

In some cases, the surfaces were etched in order to reveal the grain structure of the metallic phases. For this purpose, $2 \%$ Nital solution has been used with an etching time of $80 \mathrm{~s}$.

\subsection{Thin foils}

TEM provides crucial details regarding those microstructural features responsible for the mechanical performance at the requisite resolution. For this purpose, thin sections have been produced by mechanical dimpling, followed by ion beam thinning. Microstruc-

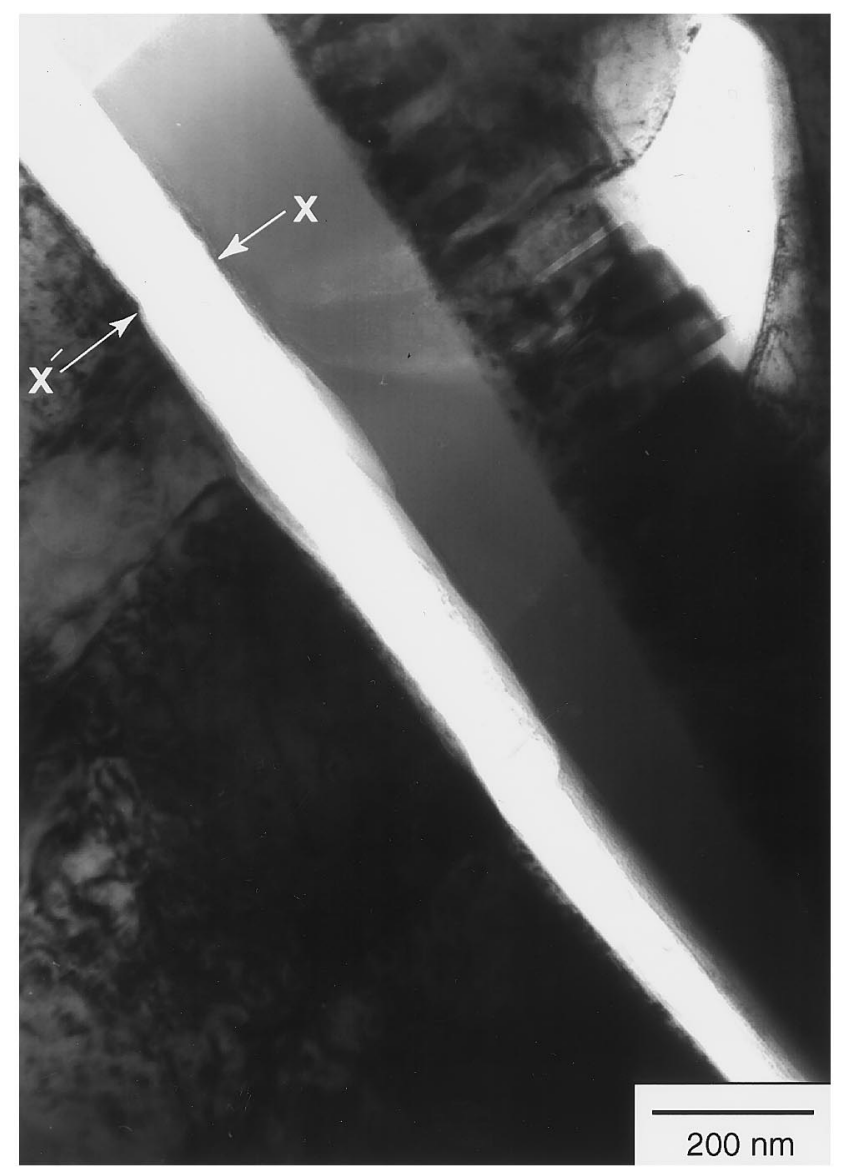

Fig. 6. Bright field transmission electron microscopy (TEM) image of microseparation formed at the interface between the amorphous oxide and the $\alpha-\mathrm{Fe}$ (formed upon thin foil preparation). The surfaces of separation are indicated by the arrows of $\mathrm{X}$ and $\mathrm{X}^{\prime}$.

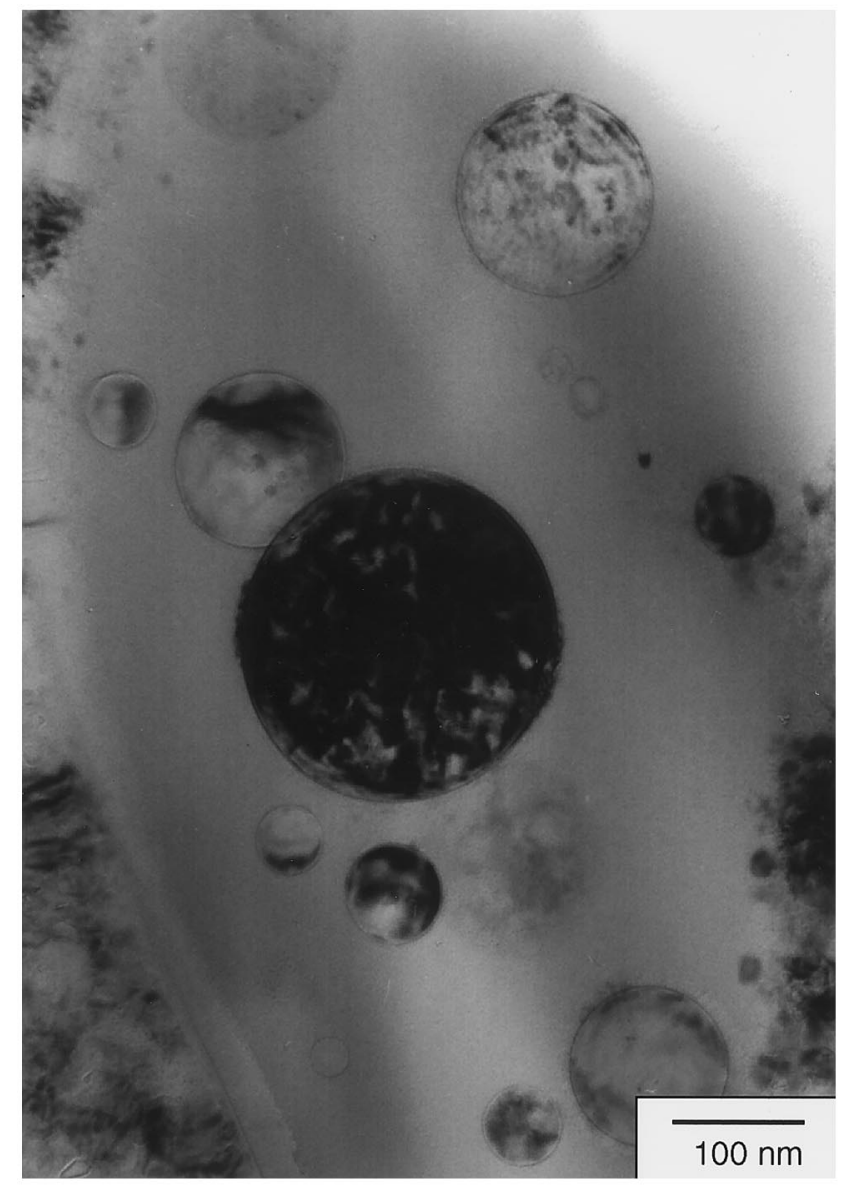

Fig. 7. Bright field transmission electron microscopy (TEM) image of one of the oxide inclusions showing the amorphous oxide matrix and crystalline $\alpha-\mathrm{Fe}$ precipitates.

tural features have been characterized by combinations of bright and dark field imaging. Selected area electron diffraction (SAD) has been used to probe crystal structures and the presence of amorphous regions. Chemical information has been obtained by energy dispersive $\mathrm{X}$-ray analysis (EDX).

\section{HVOF coatings}

Typical SEM images of polished cross sections (Fig. 1) reveal predominant regions having bright contrast: they are metallic and comprised largely of $\alpha-\mathrm{Fe}$. The intervening gray regions are oxides of $\mathrm{Fe}$ and/or $\mathrm{Al}$. Their volume fraction is sensitive to the $\mathrm{Al}$ content (Table 1).

The elementary microstructure comprises disc-shaped domains of $\alpha-\mathrm{Fe}$ with major axis parallel to the substrate surface $[15,16]$. Each domain originates from a single liquid drop that spreads laterally upon impact with the substrate. In practice, the morphology is much more complex [15-17]. The domains are distorted because they do not impact a planar surface; moreover, 
some drops fragment upon impact into smaller, more equiaxed zones. Additionally, various oxidation products form [12]. The oxide phases exert a critical influence on coating performance. One of the major goals is to characterize these oxides and establish their effect on properties.

\subsection{Standard materials}

Basic HVOF materials (without Al: categories A/B, Table 1) contain a substantial fraction of oxide (Fig. 1), which exhibits several characteristic morphologies [12]. These morphologies, referred to the SEM image (Fig. 1 ), are essentially the same as those reported elsewhere [12].

1. Large oxide domains form in the liquid state and, during impact with the substrate, distort compatibly with the Fe: region A in Fig. 1.
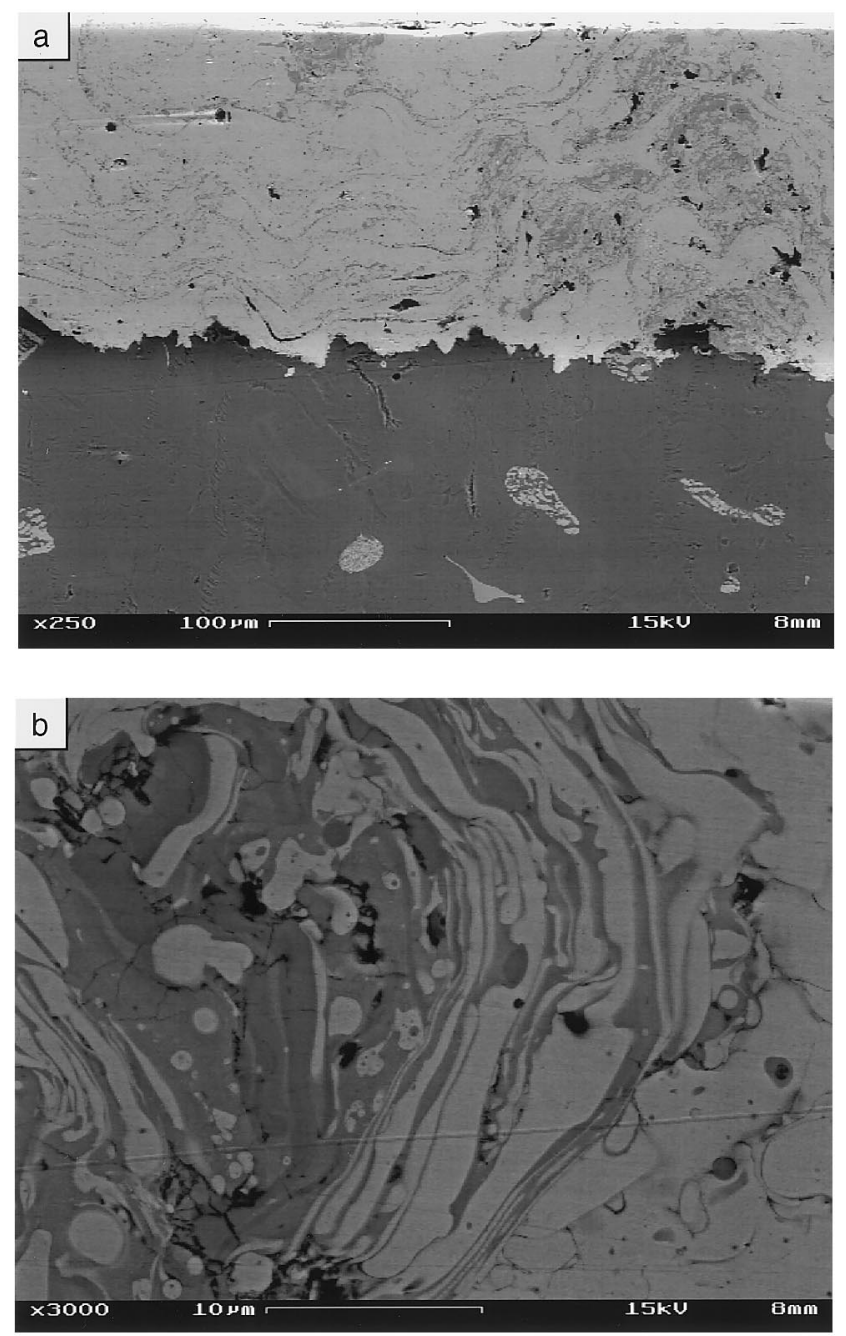

Fig. 8. Scanning electron microscopy (SEM) images of plasma transfer wire arc (PTWA) coating: (a) overview; (b) higher resolution image of one high oxide content domain.

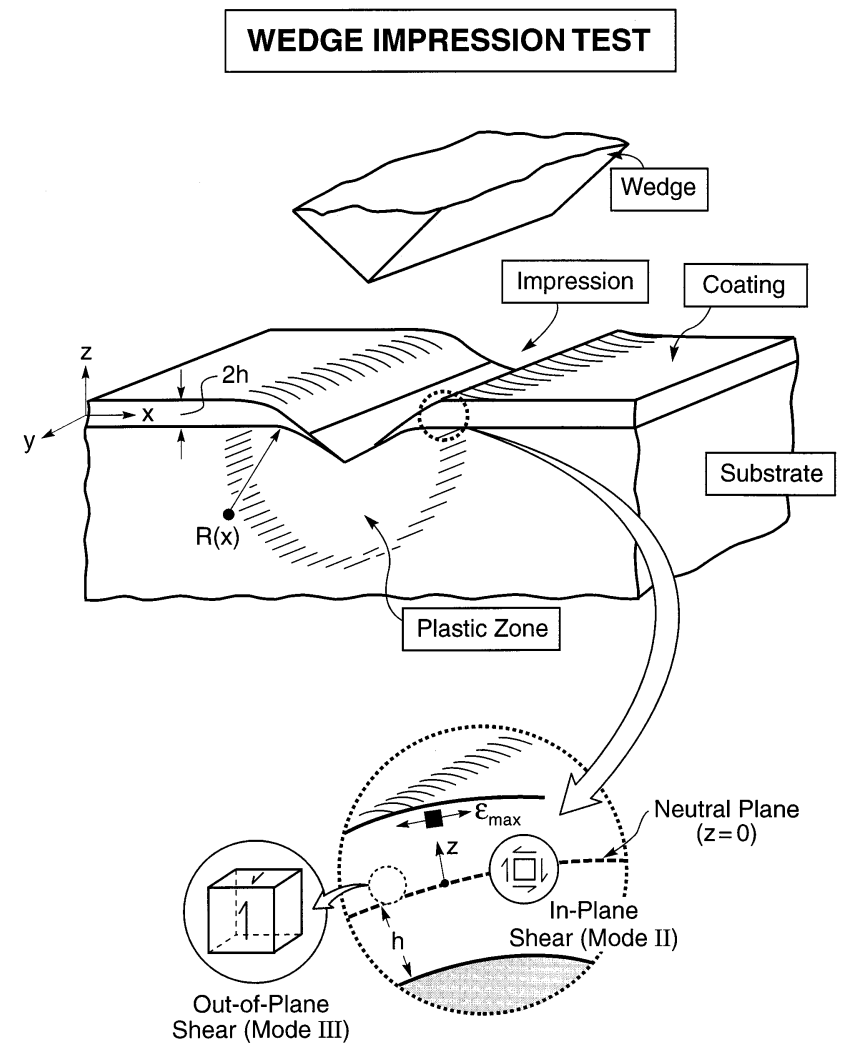

Fig. 9. A schematic showing the wedge impression test.

2. Small oxide particles present in the $\mathrm{Fe}$ are indicative of precipitates that developed in the solid state, upon cooling: region B in Fig. 1.

3. A thin oxide film between the Fe splats, believed to have developed after solidification, by oxidation of the exposed Fe surface: region $\mathrm{C}$ in Fig. 1.

Additional information has been provided by electron micro-probe analysis (EMPA). It has established that the metal phase is $\alpha-\mathrm{Fe}$ and that the oxide phase is $\mathrm{FeO}$. Moreover, spherical $\alpha-\mathrm{Fe}$ precipitates have been identified in the $\mathrm{FeO}$, as well as $\mathrm{FeO}$ precipitates in the $\alpha-\mathrm{Fe}$.

\section{2. $\mathrm{Fe} /$ Al alloys}

Appreciable differences are apparent in materials containing Al. The oxide content is considerably lower (Table 1) and dependent on the Al. SEM images (Fig. 2) reveal that oxide is present in two principal forms.

1. Oxide inclusions are apparent, with image contrast indicative of at least two phases: region X on Fig. 2.

2. Thin layers of oxide occur between all of the metallic splats: region Y on Fig. 2. These layers are more prominent than in the standard material. They are believed to have been formed by solid state oxidation of the exposed $\mathrm{Fe} / \mathrm{Al}$ after solidification.

In both morphologies, EMPA and EDX results indicate that the oxides contain $\mathrm{Fe}$ and $\mathrm{Al}$, in ratios suggestive of mixtures of $\mathrm{Al}_{2} \mathrm{O}_{3}, \mathrm{FeAl}_{2} \mathrm{O}_{4}$ and $\mathrm{FeO}$. 
Upon etching to reveal the microstructure of the ferrous domains, columnar grains are apparent (Fig. 3). Generally, the grain axes are oriented normal to the splat boundaries [17]. Etching also enhances the visibility of the thin oxide layers between splats, illustrated on Fig. 3. Note that the layer is continuous and has a thickness of about $0.1-0.2 \mu \mathrm{m}$.

The TEM measurements have established that the thin oxide layers between splats are all amorphous (Fig. 4a), as evident from the SAD patterns (Fig. 4b). Moreover, the layers have quite uniform thickness of about $200 \mathrm{~nm}$, consistent with SEM observations (Fig. 3). Chemical analysis by EDX (Fig. 5) indicates that Fe, Al and $\mathrm{O}$ are present in all cases, with variable quantities of $\mathrm{Si}$ and $\mathrm{S}$, as well as other trace elements. The adjoining material is crystalline, comprising either $\alpha-$ $\mathrm{Fe}$ or $\alpha-\mathrm{Fe}(\mathrm{Al})$. Precipitates are also evident within the grain. These are either oxides or carbides (both $\mathrm{O}$ and $\mathrm{C}$ exist in the grains), but not intermetallics.

In several instances, microseparations form during thin foil preparation. These are invariably located at
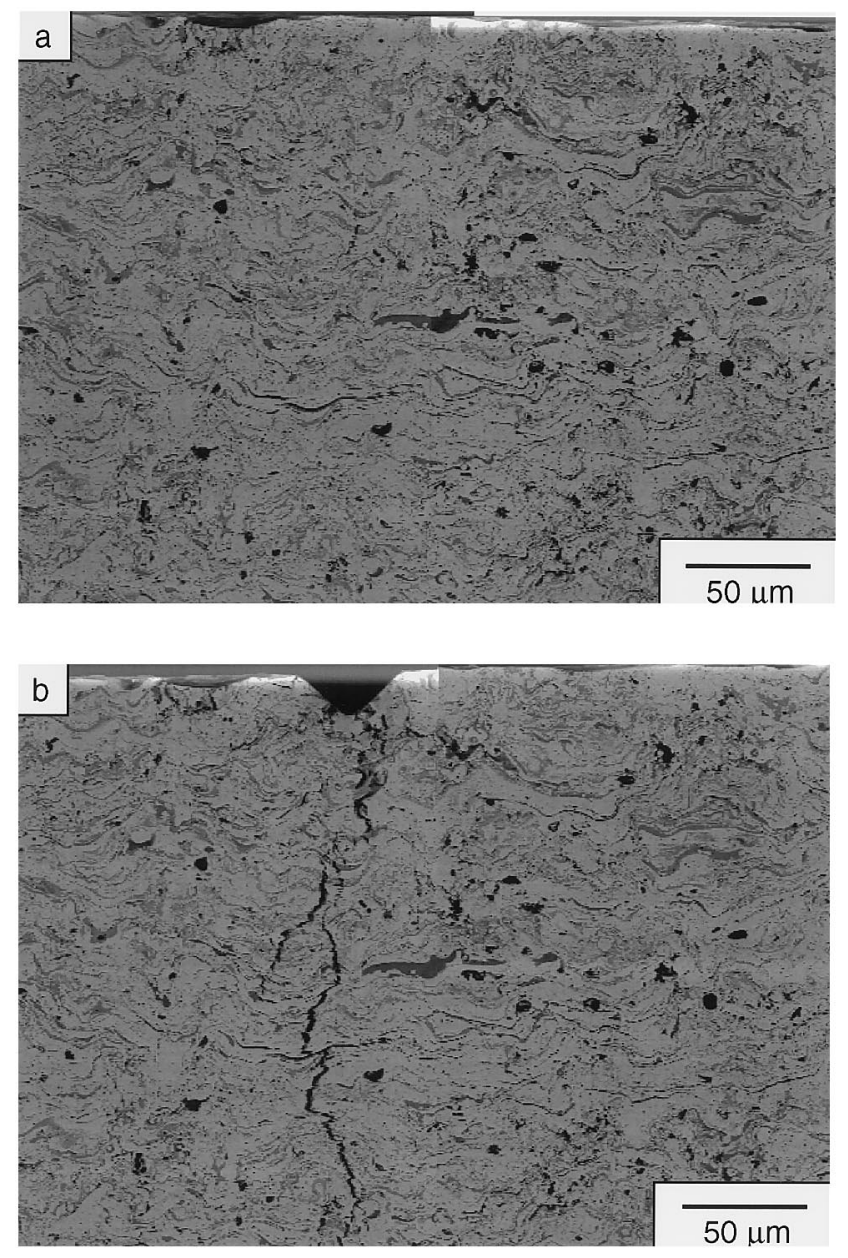

Fig. 10. Scanning electron microscopy (SEM) image showing median crack formed by wedge impression: (a) region prior to impression; (b) same region after impressing. the interface between the amorphous layer and the $\mathrm{Fe}$ (Fig. 6).

The inclusions are found to comprise an amorphous oxide matrix containing crystalline $\alpha-\mathrm{Fe}$ particles (Fig. 7). The chemical composition of the oxide is similar to that of the thin interlayers.

\section{PTWA coatings}

Coatings made by the PTWA process are qualitatively different (Fig. 8a). There are two key differences. Domains having high oxide volume fraction exist and occur with a periodicity of about $0.2-0.3 \mathrm{~mm}$ (Fig. 8 b). These domains are related to a periodicity inherent in the PTWA deposition process [6]. Between these domains, the microstructure is similar to that found in HVOF coatings having low oxygen concentrations (those made from $\mathrm{Fe} / \mathrm{Al}$ alloys) except that the splats are appreciably larger.

Thin oxide layers again exist between the splats, about $0.1-0.2 \mu \mathrm{m}$ in thickness. TEM indicates that they are amorphous. They contain $\mathrm{Fe}, \mathrm{Si}, \mathrm{O}$ and $\mathrm{S}$, with other trace elements, but are devoid of Al. Amorphous oxide inclusions containing $\mathrm{Fe}$ precipitates are also present.

\section{Testing and analysis}

\subsection{Concept}

The objectives of the measurements are to characterize quantitatively the deformation and cracking responses of the ferrous coatings, while attached to their cylindrical Al alloy substrates. For this purpose, methods have been developed that introduce strains into the coatings by controlled deformation of the substrate. While several configurations were tried, the most consistent and informative results have been obtained by using wedge impression tests. The configuration is depicted on Fig. 9. Circumferential specimens with $5 \mathrm{~mm}$ width and $15 \mathrm{~mm}$ length are cut from an aluminum cylinder with $5 \mathrm{~mm}$ thickness and $200 \mu \mathrm{m}$ coating on it. This specimen, with sides and bottom polished in the manner described in Section 2, was attached to a base plate within a servohydraulic test frame. A WC wedge indenter with an included angle of $90^{\circ}$ was located within an alignment figure that assured line contact along the apex of the wedge. Displacements were measured by means of a linear variable differential transformer (LVDT). Loads were applied at constant displacement-rate up to penetrations of about $200 \mu \mathrm{m}$. Images of the same region taken before and after impressing allow determination of displacement vectors, strains and various damage parameters. 

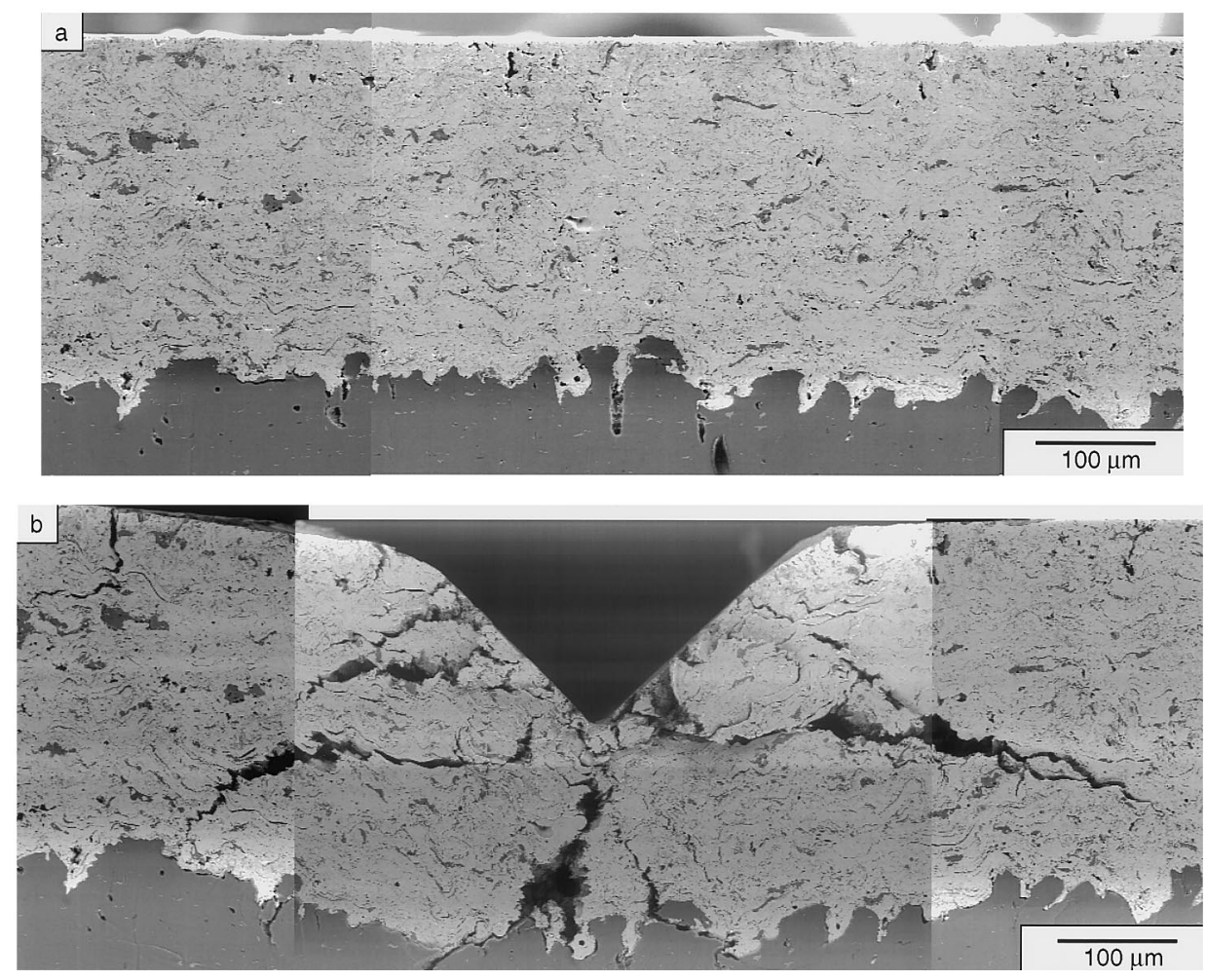

Fig. 11. Scanning electron microscopy (SEM) image showing bending and lateral cracks formed by wedge impression: (a) region prior to impression; (b) same region after impressing.

At small penetrations $(\sim 20 \mu \mathrm{m})$ median cracks form and extend through the coating (Fig. 10). Subsequent penetration causes the coating to cantilever downward by plastic deformation of the substrate (Fig. 11). These deformations introduce a distribution of small separations (see Fig. 16) in regions subject to large strain. There are normal and in-plane shear strains that induce mode I and II microseparations (Section 5.2). Some out-of-plane bulging also accompanies impression, governed by the plastic Poisson ratio of the substrate. There is an associated gradient in displacement away from the apex of the impression, resulting in strains that motivate mode III (out-of-plane shear). Fig. 12 is a schematic associated bending showing the initial median cracks followed by lateral cracking with deformation of coating into substrate.

The locations of these separations and the associated displacements are of principal interest, since they characterize the local scale fracture toughness (Section 5.3) which, in turn, governs degradation and wear. Penetrations of about $200 \mu \mathrm{m}$ were found to yield a distribution of micro-separations that can be used to adequately characterize these parameters.

\subsection{Strain assessment}

Strains in the coating caused by impression can be estimated from the local surface curvature, by using beam theory. These estimates neglect stretching and transverse strains that arise from attachment to the substrate, which are limited by the shear yield strength of the substrate.

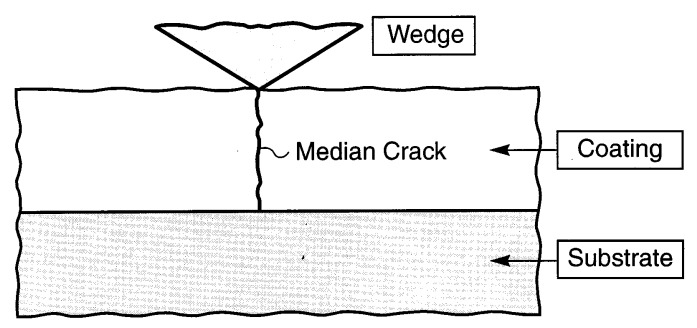

a) Median Crack

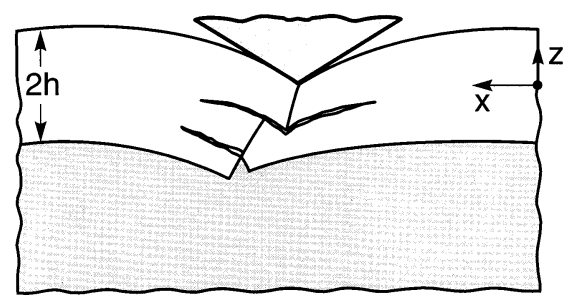

b) Bending And Lateral Cracking

Fig. 12. A schematic showing (a) initial median crack followed by (b) lateral cracking with deformation of coating into substrate. 

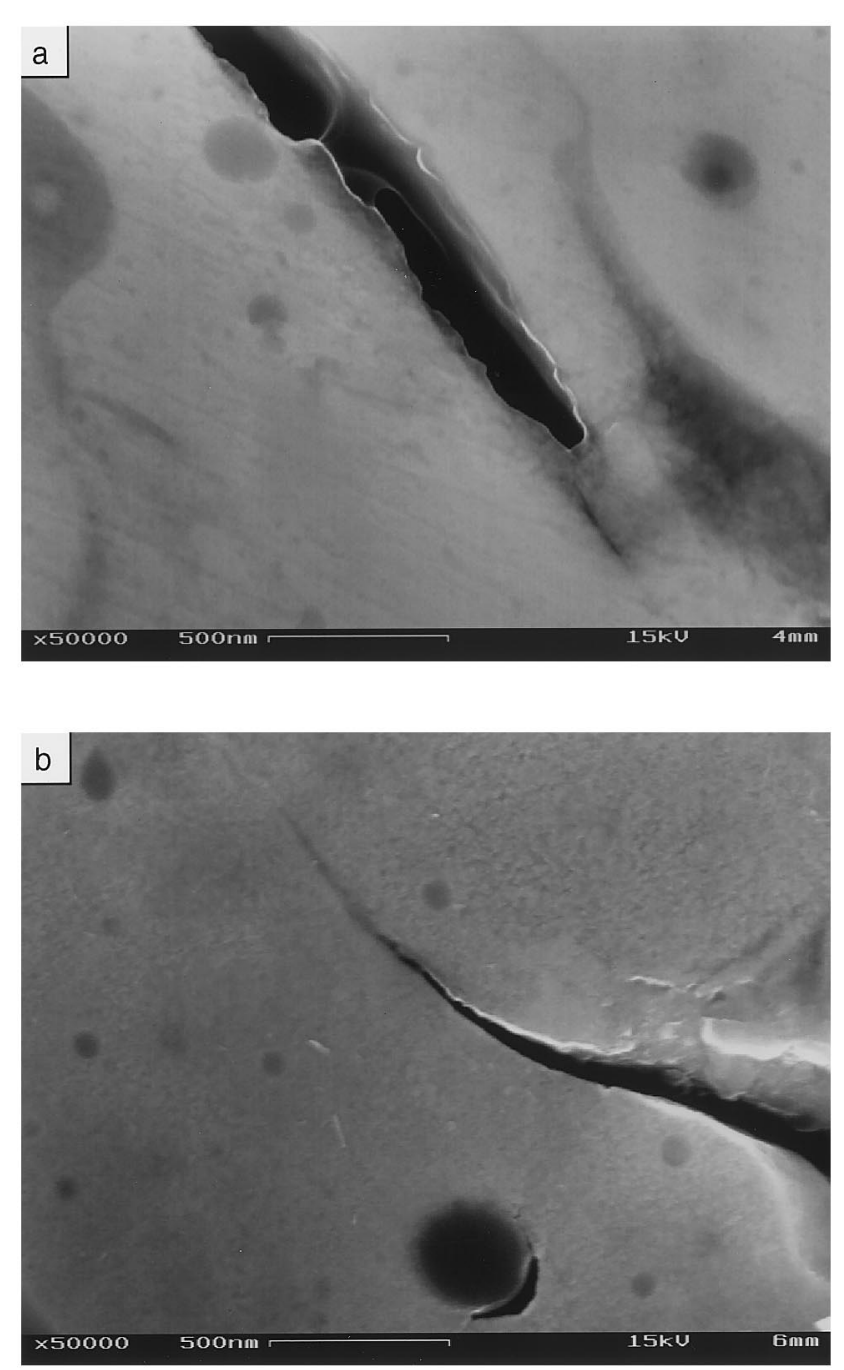

Fig. 13. Scanning electron microscopy (SEM) images of opening displacement in category $\mathrm{C}$ high velocity oxyfuel (HVOF) coatings associated with cracks located at the intersplat oxide. (a) Crack that blunts after arresting at the interface with the $\alpha-\mathrm{Fe}$. (b) Crack in the intersplat oxide that remains sharp.

The bending induced strains in the coating are related to the local radius of curvature, $R$, by (Fig. 9):

$\varepsilon=\varepsilon_{\max }(z / h)$

with

$\varepsilon_{\max }=(h / R)$

being the strain at the surface $(z=h$, positive) or at the interface ( $z=-h$, negative) and $2 h$ is the coating thickness. In turn, $R$ is related to the surface profile of the coating, $x(z)$, by

$R=\left(1+\dot{x}^{2}\right)^{3 / 2} / \ddot{x}$

where $\dot{x}=\mathrm{d} x / \mathrm{d} z$ and $\ddot{x}=\mathrm{d}^{2} x / \mathrm{d} z^{2}$.

The in-plane shear strains are related to the variation in $R$ with spatial location, $x$, along the coating, given by: $\gamma=\gamma_{\max }\left[1-(z / h)^{2}\right]$

with

$\gamma_{\max }=(h / R)^{2}(1-v)(\mathrm{d} R / \mathrm{d} x)$

Consequently, by measuring the shape $x(z)$ of the deformed surface, the bending and shear strains can be estimated, as described in Section 6.

\subsection{Toughness estimation}

General observations of those separations (induced by impression) located within the thin oxide layer at the splat boundaries indicate a relatively constant opening or shear displacement along their central region (see Fig. 16). Such constancy is suggestive of steady-state cracking, analogous to that found in thin films. The displacements near the crack tip, $\delta(x)$, as well as in the steady-state region, $\delta_{\mathrm{ss}}$, may both be used to assess the local toughness.

Simulations of growing mode I cracks within elastic/ plastic solids subject to small scale yielding [18] indicate that the relationship between near-tip the crack opening profile $\delta(x)$ and the stress intensity factor, $K_{\mathrm{I}}$, is insensitive to the plasticity. Consequently, regardless of the plasticity, an analytic fit may be used to assess the mode I toughness, $K_{\mathrm{IC}}$, from measurements of $\delta(x)$ made near the tip, in accordance with [18]:

$E \delta / \sigma_{0} x=5.08 \ln \left[0.28 e\left(K_{\mathrm{IC}} / \sigma_{0} \sqrt{x}\right)^{2}\right]$

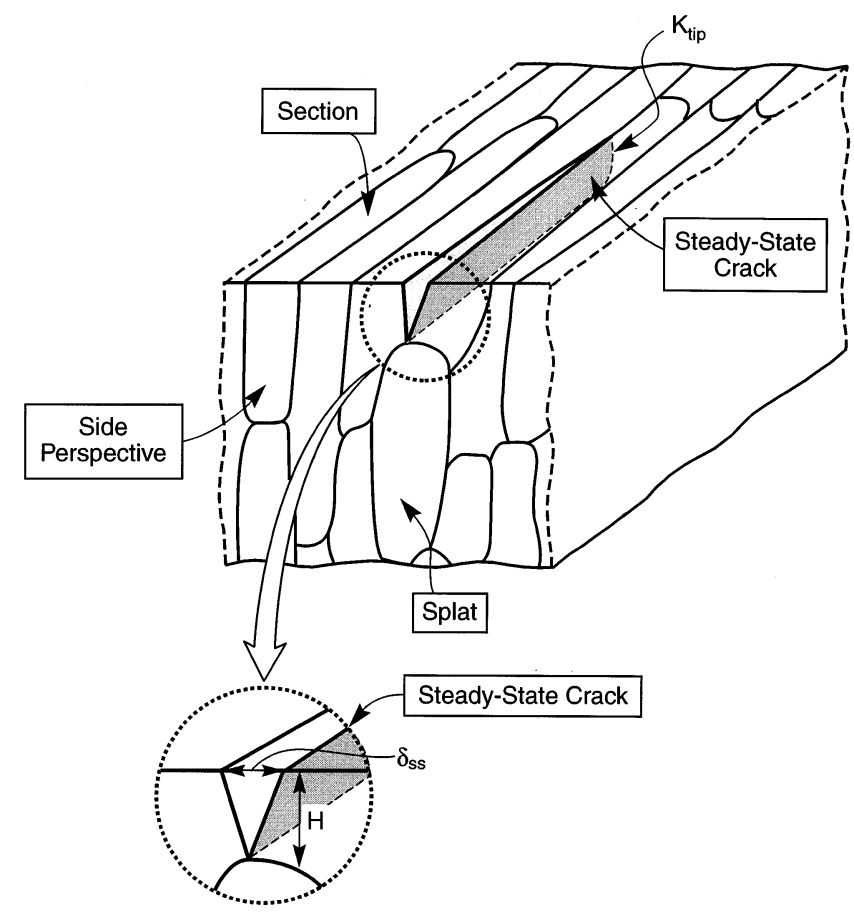

Fig. 14. A schematic illustrating steady-state cracks forming within the intersplat oxide layer. 

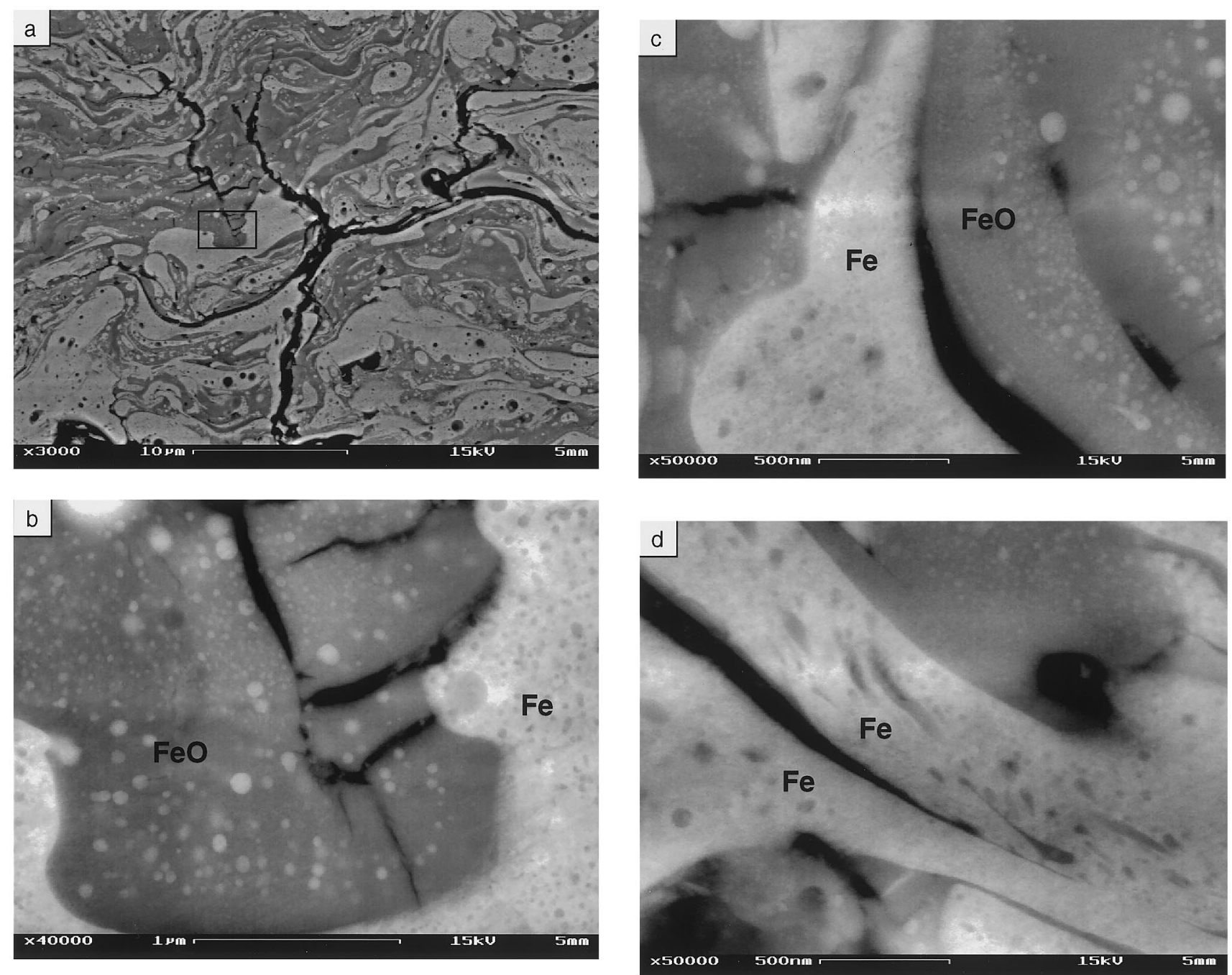

Fig. 15. (a) Scanning electron microscopy (SEM) image of thermal misfit crack formed in category A/B high velocity oxyfuel (HVOF) coatings. And higher resolution SEM images showing propagation of thermal cracks: (b) within the $\mathrm{FeO}$; (c) along the $\mathrm{Fe} / \mathrm{FeO}$ interface; and (d) along the intersplat oxide.

where $x$ is the distance from the crack tip, $\sigma_{0}$ is the yield strength of the metal and $E$ the Young's modulus. This result is used in Section 6 to estimate $K_{\mathrm{IC}}$ for separations at intersplat boundaries.

In some cases, cracks arrest at the oxide/metal interface and blunt by plastic flow in the $\alpha-\mathrm{Fe}$ (see Fig. 13). In such instances, the stress intensity factor relevant to the crack tip zone $K_{\mathrm{E}}$ can be estimated using the $J$-integral. It is given by [19]:

$K_{t} \approx \sqrt{\beta E \sigma_{0} \delta_{0}}$

where $\delta_{0}$ is the tip opening displacement and $\beta$ is about 0.5 .

For steady-state cracks to exist, the crack depth must be restricted. The situation envisaged (Fig. 14) comprises cracks having extensions into the coating impeded by neighboring splats. This depth, $H$, then becomes the length dimension that governs the tip stress intensity factor. For a mode I crack, the steadystate $K$ is related to the stress, $\sigma$, in the layer by [20,21]:

$K_{\mathrm{I}}=1.12 \sigma \sqrt{\pi H / 2}$

But, the stress and the surface opening displacement are related by [20]:

$\delta_{\mathrm{ss}}=5.82 H \sigma / E$

Eliminating $\sigma$ from Eqs. (6) and (7) allows the critical stress intensity factor to be related to the opening by:

$K_{\mathrm{IC}} \equiv(0.19 \sqrt{\pi}) E \delta_{\mathrm{ss}} / \sqrt{2 H}$

The mode III result is the same, but with the opening displacement replaced by the surface step height, $d_{\mathrm{ss}}$ :

$K_{\text {IIIC }}=(0.19 \sqrt{\pi}) E d_{\text {ss }} / \sqrt{2 H}$ 


\section{Measurements and observations}

\subsection{Misfit cracks}

The category A/B HVOF materials (Table 1) all exhibited periodic cracking when thin annular sections were made by electron discharge machine EDM. The cracks are typically separated by $0.3-0.5 \mathrm{~mm}$ and extend partially through the thickness (Fig. 15a). Locally, the cracks bifurcate and extend parallel to the substrate, often over considerable distances. Higher resolution images of these cracks reveal important characteristics (Fig. 15b-d). (i) The cracks are located primarily within the oxide, but at some sites, appear to be along the $\mathrm{Fe} / \mathrm{FeO}$ interface. (ii) Cracks never penetrate the $\mathrm{Fe}$, but instead, blunt plastically, indicative of ductility in the metal (Fig. 15c). Near the tip, within the oxide, the crack opening displacements are small (Fig. 15b), signifying a low toughness (Eq. (4)). Given the presence of these cracks, impression tests are not required.

\subsection{Impression induced cracks}

The results of impression tests performed on category $\mathrm{C}-\mathrm{E}$ HVOF and PTWA coatings are summarized on Fig. 16a-d. Corresponding images of polished surfaces before and after impression reveal those microstructural features most susceptible to microcracking. Upon inspection, in both materials, the thin oxide layers between splats comprise the dominant sites for cracking. Perhaps surprisingly, the thicker oxides and the inclusions are relatively resistant to cracking. An occasional inclusion crack exists, but these are sparse. Cracks are present in only a few of the larger oxide domains. Moreover, the periodic oxide domains in the PTWA
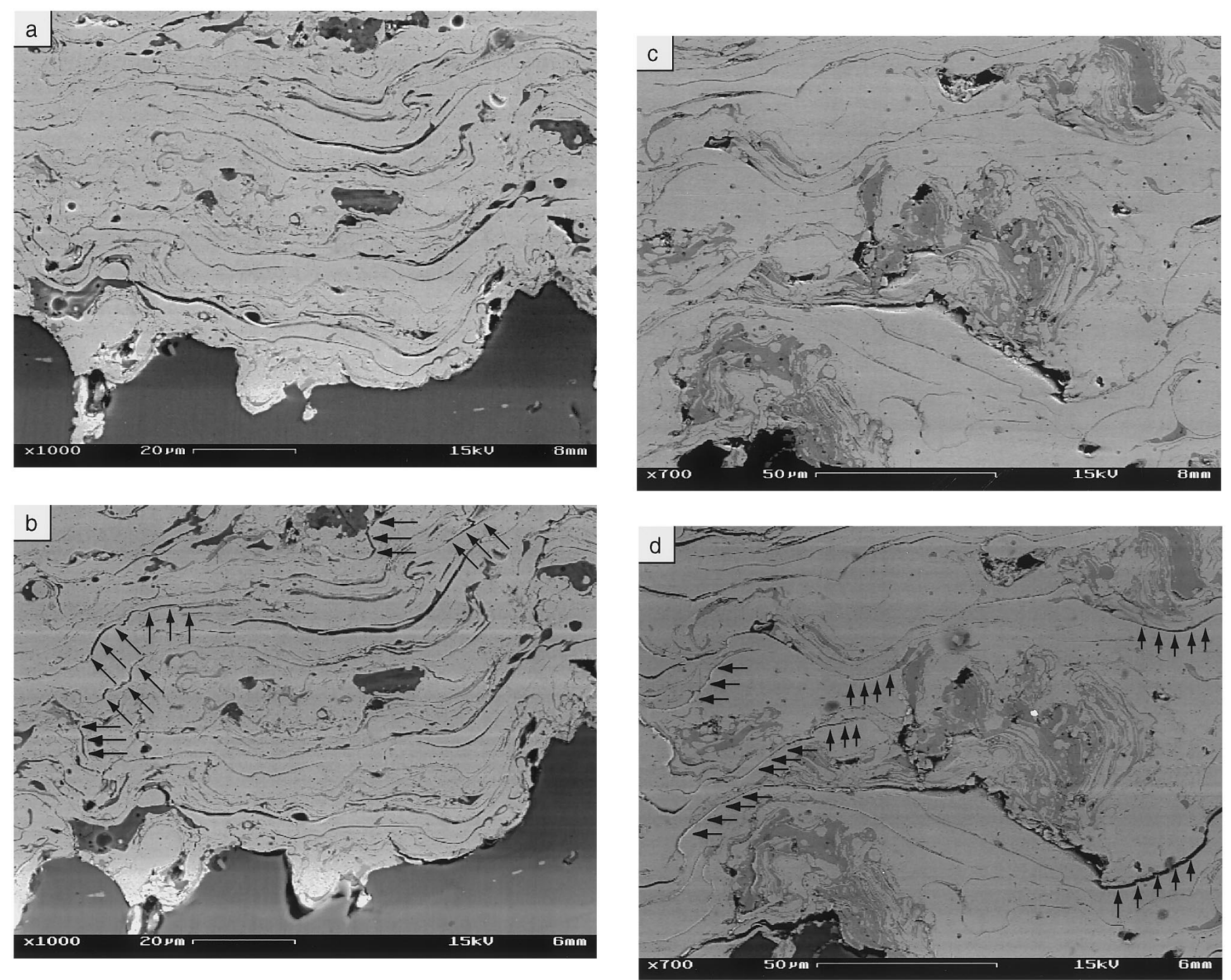

Fig. 16. Images of regions within cross sections taken before and after wedge impression. These images are used to identify those microstrucutural features most susceptible to cracking. (a, b) High velocity oxyfuel (HVOF) coating, category C. (c, d) Plasma transfer wire arc (PTWA) coating. The cracks that form are marked with arrows. Note that they all develop at thin intersplat oxide layers that are barely visible in the coating prior to impressing. 

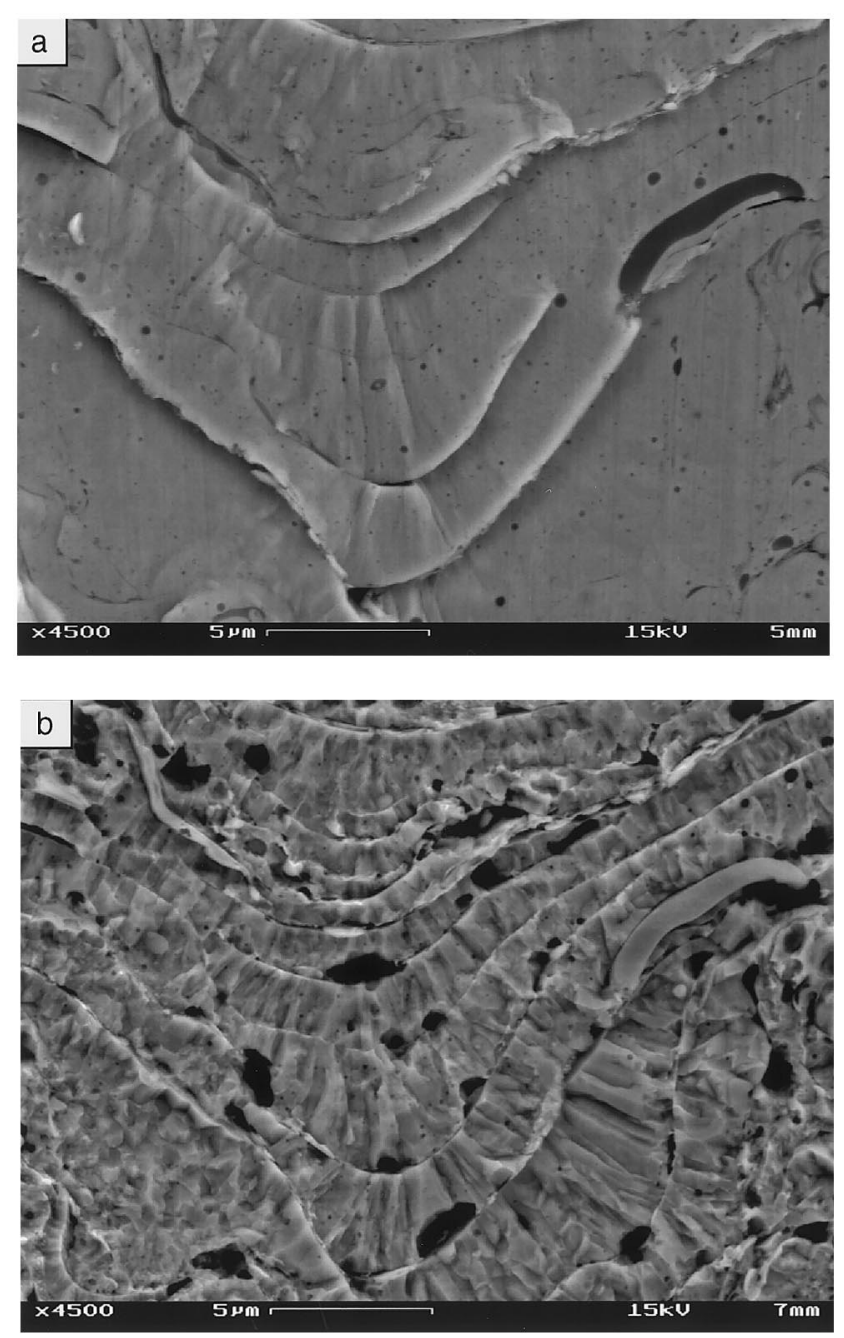

Fig. 17. Scanning electron microscopy (SEM) images of a plastically deformed region: (a) after impressing, (b) after etching the same region.

coatings appear to be capable of significant deformation without destructive cracking.

Comparisons of many superposed images have established that the incidence of separations is not predictable from the most obvious morphological characteristics. The only consistent feature is the preference for separations to occur at certain thin intersplat oxides. There are no indications of slip lines in the $\mathrm{Fe}$ adjacent to these interlayer cracks, even at AFM resolutions.

In some regions, other topographies created by impression may have relevance to coating performance. An example is presented on Fig. 17. Note the presence of bands within the metal domains aligned along the grain boundaries of the columnar structure. These sig-
Table 2

Mechanical properties of high velocity oxyfuel (HVOF) coatings measured by nanoindentation [14]

\begin{tabular}{ll}
\hline Young's modulus & $\mathrm{E}=200 \pm 50 \mathrm{Gpa}$ \\
Hardness & $H=3 \mathrm{GPa}$ \\
Yield strength & $\sigma_{0} \approx H / 3$
\end{tabular}

nify that each grain distorts relative to its neighbors, but there is no evidence of slip lines. It is also notable that, upon etching, voids appear in this region of the coating. The reasons are not yet understood, but may be strain related.

\subsection{Critical strains}

By measuring the surface shape of the impressed coatings, $x(z)$, as indicated on Fig. 9, the bending and shear strains have been estimated using Eqs. (1a), (1b), (3a) and (3b). The surface profiles have been found to fit a second order polynomial with a regression coefficient, $R=0.997$. Differentiation gives the curvature and its gradient. In the domain near the impression where the intersplat separations arise, the maximum bending strain ranges from 0.20 to $0.30 \%$, over a distance, $x \approx 240 \mu \mathrm{m}$; whereas the maximum shear strains are only $0.02 \%$.

For the Al containing HVOF materials, as well as the PTWA materials, the bending strains at which separations first appear are about $0.25 \%$. Conversely, in the category $\mathrm{A} / \mathrm{B}$ HVOF materials, cracks in the $\mathrm{FeO}$ arise at appreciably smaller strains, of order $0.1 \%$.

\subsection{Local fracture toughnesses}

In category A/B HVOF coating measurements of the opening profile, $\delta(x)$, have been made for several cracks, using the SEM at high resolution. These profiles have been introduced into Eq. (4) with the properties listed on Table 2 [22] to evaluate the mode I toughness. For the cracks examined, $K_{\mathrm{IC}}$ ranges from 0.6 to 1.5 $\mathrm{MPa} \sqrt{ } \mathrm{m}$ when the cracks are located near $\mathrm{Fe} / \mathrm{FeO}$ interfaces, and from 0.7 to $0.9 \mathrm{MPa} \sqrt{\mathrm{m}}$ when the cracks are at intersplat boundaries. For the cracks located entirely within the $\mathrm{FeO}, K_{\mathrm{IC}}$ ranges from 0.55 to $0.8 \mathrm{MPa} \sqrt{\mathrm{m}}$.

In category $\mathrm{C}-\mathrm{E} \mathrm{HVOF}$, as well as PWTA, coatings, some separations present at the oxide interlayers exhibit opening displacements (mode I). Examples are shown on Fig. 13. Others have out-of-plane steps (mode III),

Fig. 18. Step height at various distances from the crack tip for the mode III intersplat cracks identified in Fig. 17, measured using the atomic force microscope (AFM). (a) Topographical image of steps with a $z$ range $0-1500 \mathrm{~nm}$. (b) Surface profile of the steps with a $z$ range of $0-1.5 \mathrm{~V}$. (c) Step height traces showing the surface height at locations relative to the crack tip for the mode III intersplat crack identified within a box in (a). Each color represents information referred to the line having the same color identified in (a). 
Fig. 18. 
Figs. 17 and 18. In mode I, various behaviors have been found. In some cases, cracks within the oxide arrest at the metal/oxide interface and blunt by plastic flow in the $\alpha-\mathrm{Fe}$ (Fig. 13a). For such cracks, a tip stress intensity factor can be assessed from Eqs. (8a) and (8b). It is in the range from 0.6 to $1.5 \mathrm{MPa} \sqrt{ }$. In other instances, cracks extend along the interface and remain sharp, with small opening displacements (Fig. 13b). For these interface cracks, Eq. (4) may be used to estimate the local mode I toughness using the mechanical properties from Table 2. Among the cracks examined, $K_{\mathrm{IC}}$ ranges from 0.6 to $1 \mathrm{MPa} \sqrt{\mathrm{m}}$.

The local mode III toughness has been estimated from shear displacements (Fig. 18). For this purpose, step heights in steady-state, $d_{\mathrm{ss}}$, have been measured on several separations, by using an atomic force microscope. A series of traces made normal to the plane of one such interlayer crack reveal the steady-state domain. The average step height is found to be $d_{\mathrm{ss}} \approx$ $400 \mathrm{~nm}$. The toughness is somewhat sensitive to the choice made for the crack depth, $H$. Assuming that this is about equal to the splat radius (see Fig. 14), then for the HVOF coatings, $H \approx 18 \mu \mathrm{m}$, such that with Eq. (7): $K_{\mathrm{IC}} \approx 4 \mathrm{MPa} \sqrt{\mathrm{m}}$ (or $80 \mathrm{~J} \mathrm{~m}^{-2}$ ).

\section{Implications}

\subsection{Microstucture evolution}

The liquid drops that form at the wire source are susceptible to oxidation during transit to the substrate. When $\mathrm{FeO}$ forms at this stage, it is a liquid, immiscible with $\mathrm{Fe}[12,23]$, resulting in intermixed oxide/metal domains having size of order the drop radius. Both domains flow laterally upon impact with the substrate, resulting in disk domains of $\mathrm{FeO}$ and $\mathrm{Fe}$ evident in standard HVOF coatings (Fig. 1) $[12,17]$. Such domains also occur periodically in the PTWA coatings (Fig. 8). Subsequent to solidification, precipitation occurs in both phases. The Fe precipitates in $\mathrm{FeO}$ are predominant, because of temperature dependent reductions in the solubility of $\mathrm{Fe}$ in $\mathrm{FeO}$.

The liquid state behavior differs when alloying elements are present, because oxides other than $\mathrm{FeO}$ have a greater free energy of formation. Such oxides, once formed, are likely to remain solid. Coatings made from $\mathrm{Fe} / \mathrm{Al}$ alloys illustrate the difference. Now, $\mathrm{Al}_{2} \mathrm{O}_{3}$ should be the oxide having the greatest free energy of formation. It is solid at the melting temperature of $\mathrm{Fe}$. Moreover, when the $\mathrm{Al}$ is locally depleted, spinel $\left(\mathrm{FeAl}_{2} \mathrm{O}_{4}\right)$ would become the preferred oxide, which is also solid at the Fe melting temperature. However, all of the oxides found in these materials are amorphous, with appreciable amounts of $\mathrm{Al}$ and Fe. Amorphous Al-containing oxides are generally a consequences of either a high silica content, resulting in aluminosilicate glass, or rapid quenching from a liquid. Alternatively, they may occur upon oxidation in the solid state. While aluminosilicate formation is ubiquitous, the minimal $\mathrm{Si}$ content in these coatings suggests that the other phenomena are more pertinent.

The inclusions containing the $\mathrm{Fe}$ precipitates are unlikely to be the result of solid state oxidation. These presumably form as an $(\mathrm{Al}, \mathrm{Fe}) \mathrm{O}$ liquid during drop transit. Thereafter, the $\mathrm{Fe}$ precipitates in the solid state as its solubility decreases on cooling. The intersplat oxide is believed to have a different origin for two reasons: it has a relatively uniform thickness and it is devoid of $\mathrm{Fe}$ precipitates. These two features suggest that it is formed by oxidation in the solid state. That the thickness exceeds that predicted for $\mathrm{FeO}$ formation on $\mathrm{Fe}$ (only, 10-50 nm) [12], reflects the amorphous nature of the oxide.

\subsection{Fracture toughness}

Cracks propagate along the interface between the amorphous oxide interlayers and $\alpha-\mathrm{Fe}$ with mode I fracture toughness $<1 \mathrm{MPa} \sqrt{ }$ m (or $<5 \mathrm{~J} \mathrm{~m}^{-2}$ ). This level is below that found for bulk amorphous oxides [24,25]. Such low values are consistent with an absence of crack induced plastic deformation in the $\mathrm{Fe}$, and indicative of a weak interface. The toughness is higher in mode III because friction along the crack surface reduces the shear transmitted to the crack tip, analogous to other shielding phenomena [25].

The low toughness severely limits the performance of these coatings, causing them to be susceptible to splat delamination upon frictional loading. Identifying deposition conditions that would either eliminate the oxide layer, or induce crystallization, should substantially enhance durability.

\section{Summary}

A major finding of the study is that in both HVOF and PTWA coatings, thin amorphous oxide layers exist between $\alpha-\mathrm{Fe}$ splats. These layers have low adherence to the $\alpha-\mathrm{Fe}$, resulting in a local mode I interfacial fracture toughness of only 0.2 to $1 \mathrm{MPa} \sqrt{\mathrm{m}}$, lower than that for bulk oxide glasses. Higher toughnesses exist in mode III, because of frictional load transfer across the crack faces. Because of its thinness and uniformity, it has been proposed that the intersplat oxide is formed by solid state oxidation. Implementing approaches that inhibit such oxidation would substantially enhance the durability of the coating. 


\section{References}

[1] R.C. McCune, Weld. J. 24 (1995) 41-47.

[2] M.R. Kim, R.W. Smith, R.C. McCune, in: C.C. Berndt, S. Sampath (Eds.), Proc. 7th National Thermal Spray Conference, ASM International, Materials Park, OH, 1994, p. 43.

[3] M.S. Kramer, L.E. Burns, G.L. Holmes, Method and apparatus for application of thermal spray coatings to engine blocks. US Patent 5,271,967, 1993.

[4] M.S. Kramer, C.J. Rivard, F.A. Koltuniak, Thermally sprayed aluminum bronze coatings on aluminum engine bores. US Patent 5,080,056, 1992.

[5] D.R. Marantz, K.A Kowalsky, High velocity electric arc spray apparatus and method of forming materials. US Patent 5,296,667, 1994.

[6] J.A. Browing, Double arc prevention for a transferred-arc flame spray system. US Patent 4,762,977, August 9, 1988.

[7] S.E. Hartfield-Wunsch, S.C. Tung, in: C.C. Berndt, S. Sampath (Eds.), Thermal Spray Industrial Applications, ASM International, Metals Park, OH, 1994, pp. 19-24.

[8] K. Korpiola, J.-P. Hirvonen, H. Jalkanen, L. Lasts, F. Ross, in: C.C. Berndt, S. Sampath (Eds.), Thermal Spray Science and Technology, ASM International, Metals Park, OH, 1995, pp. $181-185$.

[9] A. Vardelle, P. Fauchais, N.J. Themelis, in: C.C. Berndt, S. Sampath (Eds.), Thermal Spray Science and Technology, ASM International, Metals Park, OH, 1995, pp. 170-180.

[10] R.A. Neiser, J.E. Brockman, T.J. O'Hearn, R.C. Dykhulzen, M.F. Smith, T.J. Roemer, R.W. Teets, in: C.C. Berndt, S. Sampath (Eds.), Thermal Spray Science and Technology, ASM International, Metals Park, OH, 1995, pp. 99-104.
[11] C.M. Hackett, G.S. Settles, in: C.C. Berndt, S.S. Sampath (Eds.), Thermal Spray Science and Technology, ASM International, Metals Park, OH, 1995, pp. 21-29.

[12] R.A. Neiser, M.F. Smith, R.C. Dykhulzen, J. Thermal Spray Technol. 7 (1998) 537-545.

[13] Automotive News Market Data Book.

[14] D.R. Marantz, K.A. Kowalsy, J.R. Baughman, D. Cook, M.J. Zaluzec, Proc. Materials for Energy Efficient Vehicles Conference, 20th Int. Symp. on Automotive Technology and Automation, Florence, Italy, June, 1996.

[15] S. Fantasi, M. Vardelle, A. Vardelle, P Fauchais, in: C.C. Berndt, T.F. Bernecki (Eds.), Thermal Spray Research, Design and Application, ASM International, Metals Park, OH, 1993, pp. $1-6$.

[16] C. Moreau, P. Cielo, M. Lamontagne, in: C.C. Berndt (Ed.), Thermal Spray: International Advances in Coatings Technology, ASM International, Metals Park, OH, 1992, pp. 761-766.

[17] S. Sampath, H. Herman, J. Thermal Spray Technol. 5 (1996) 445.

[18] R.H. Dean, J.W. Hutchinson, ASTM STP 700 (1980) 383-405.

[19] J.W. Hutchinson, Non Linear Fracture Mechanics, Technical University, Denmark, 1980.

[20] H. Tada, P. Paris, G. Irwin, Handbook of Stress Intensity Factors, Dell Research, 1985.

[21] J.W. Hutchinson, Z. Suo, Adv. Appl. Mech. 29 (1991) 63.

[22] J.W. Meng, G.M. Research (1998), private communication.

[23] G.J. Shubat, M.B. Bever, T. Lyman (Eds.), Metals Handbook, 8th edition, vol. 8, ASM International, Metals Park, OH, 1973, p. 304 .

[24] S.M. Wiederhorn, J. Am. Ceram. Soc. 50 (1967) 407-414.

[25] J.B. Wachtman, Mechanical Properties of Ceramics, Wiley, New York, 1996. 